\title{
Enhancement of Efficiency in E-Vehicle Using Hybrid Energy
}

\author{
Chitra Selvi $\mathrm{S}$ a, 1 \\ a Assistant Professor,Dept of EEE, \\ University College of Engineering, Thirukkuvalai, TamilNadu, India
}

\begin{abstract}
In the current world due to scarcity of fossil fuel, an alternative energy is required. And now thanks to shortage of gasoline in future and its dangerous impact on the environment, and its necessary to develop an alternate power to give solution for insufficient energy source. Electric motors are creating noise but we want very smooth noise-less operation and have more efficiency as compared to the traditional Engines. Wind generation is smooth and sustainable that has to be absolutely utilized by the car industry. Solar electricity is harvested by PVarrays, the terminal voltage of Photovoltaic arrays switched through a DC/DC converter to buck boost converter. Then, we are going to hybrid those energy and use it to run the vehicle. we increased the efficiency by way of using $80 \%$ on direct usage and $20 \%$ for battery charging.
\end{abstract}

Keywords. Hybrid energy, improved efficiency, Buck boost converter, ecofriendly

\section{Introduction}

An electric vehicle, additionally referred to as associate E-Vehicle (eV), uses one or additional traction motor or electric motors for propulsion. an E-vehicle is also battery- powered over a collector system by electricity from off-vehicle sources, or is also self- contained with a solar panel, battery or an electrical generator for converting fuel into electricity. In this model the solar and wind energy were hybrid and used. This model is meant primarily based upon few concepts considering the extra environment friendly use of the sources and consequently the minimal quantity of pollution related issues. aside from being extra a green-car in phrases of 0 pollution, this could even be more affordable and efficient as compared to engine pushed vehicles. The traditional electric unearths the problem of charging it after some time, the hybrid energy is used to charge the batteries. however, the solar and wind powered automobile assist to put off this downside as this vehicle has the power to be charged on board. Here, electricity is generated from wind generators and therefore the solar plates are directed to the battery for the charging. The battery can be recharged on board and consequently the car doesn't get to be standby for charging. So, we hybrid the energy supply and utilizing max power on running and minimal for battery copy.

\footnotetext{
${ }^{1}$ Chitra Selvi S, Assistant professor, Dep of EEE,University College of Engineering, Thirukkuvalai,India; E-mail: chitraselvieee@gmail.com
} 


\section{Energy Generation}

There are two stages involved in energy generation, they are,

1. Solar Energy Generation

2. Wind Energy Generation

\subsection{Solar Energy Generation}

Solar energy is radiant light and heat from the Sun that is harnessed using a range of ever-evolving technologies such as photovoltaics, solar heating, architecture, moltensalt power plants, solar thermal energy, and artificial photosynthesis. It is a significant wellspring of sustainable power source and its improvements are extensively portrayed as either dynamic sun powered or detached sun based relying upon how they catch and deliver sun-oriented vitality or convert it into sunlight-based force. Dynamic sunlight-based procedures include the usage of photovoltaic frameworks, concentrated sun-based force and sun powered water warming to saddle the vitality. Detached sun powered strategies include situating a structure to the Sun, choosing materials with light-scattering properties or positive warm mass, and planning spaces that normally circle air.

The enormous extent of sun powered vitality accessible makes it a profoundly engaging wellspring of power. The United Nations Development Program in its 2000 World Energy Assessment found that the yearly capability of sunlight-based vitality was 1,575-49,837 exajoules (EJ). This is a few times bigger than the cote world vitality utilization, which was 559.8 EJ in 2012.

The Earth receives 174 petawatts (PW) of incoming solar radiation (insolation) at the upper atmosphere.[5] Approximately 30\% is reflected back to space while the remaining is absorbed by oceans, cloudsand land masses. The spectrum of solar light at the Earth's surface is mostly spread across the visible and near-infrared ranges with a small part in the near-ultraviolet.[6] Most of the world's population live in areas with insolation levels of $150-300$ watts $/ \mathrm{m}^{2}$, or $3.5-7.0 \mathrm{kWh} / \mathrm{m}^{2}$ perday. The annual solar energy potential in south asia region is varies from 39.9 exajouls to 1339 exajouls

In our project we are going to place the solar panel on the top of the car. By placing the solar panel on the top of the car it was able to produce electrical energy. The generating electrical energy was converted using DC-DC converter through Buck boost converter.

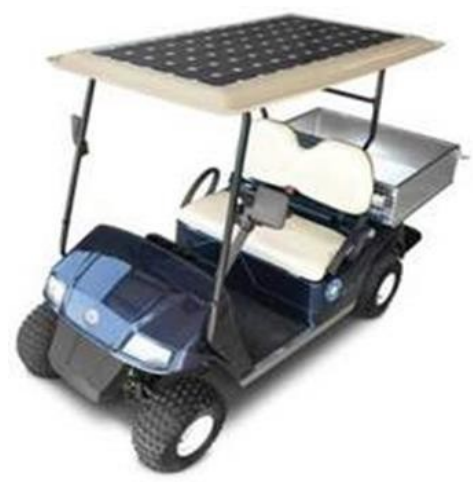

Figure 1. Solar Powered Electric Vehicle 


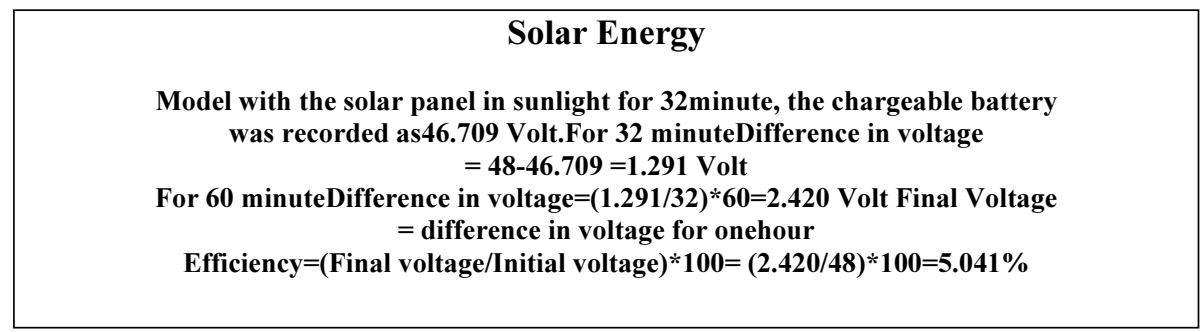

\subsection{Wind Energy Generation}

Wind energy or wind power is the use of wind to provide the mechanical power over wind turbines to turn electric generators and traditionally to do other work, like pumping or milling. Wind power is a sustainable and has a much smaller effect on the environment compared to burning fossil fuels. When we were on a trip sometime back, we were driving with the windows down, I noticed that there was wind pushing in the opposite direction. The vehicle will have multiple small wind turbines connected to the vehicle's battery. While the vehicle is in motion, the wind created around it will turn the blades, generating electricity which will charge the battery continuously. For this venture, wind vitality is being changed into power to charge the battery.

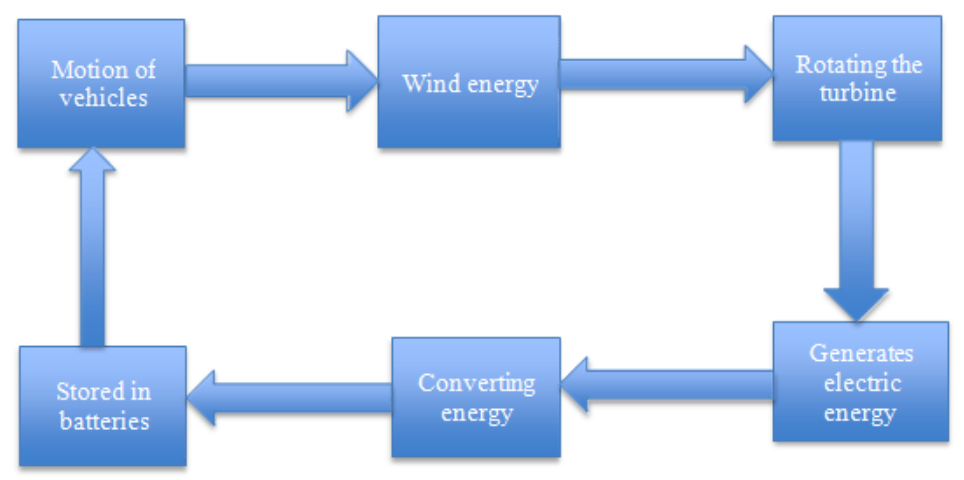

Figure 2. Wind Energy Generation

The above flow chart shows that how the wind energy was generated and used. We are generating the energy and converting it to store in battery for usage.

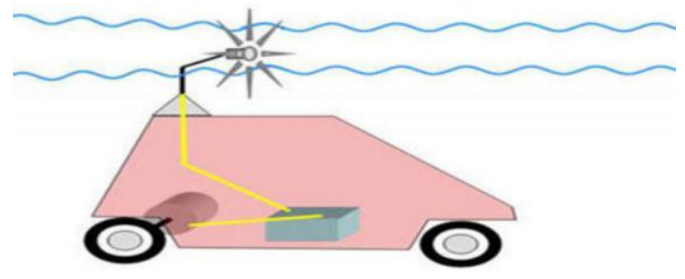

Figure 3. Wind Powered Electric Vehicle 


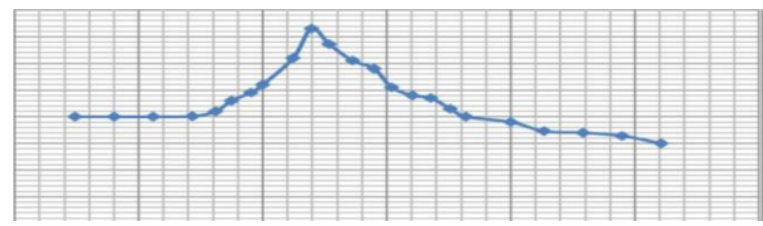

Figure 4. Wind Speed Ratio During Running Of Vehicle

Wind Energy
For 100 rotations,
Difference in voltage $=46.592-45.402=1.19$ Volt.
Final Voltage $=$ difference in voltage for 100
rotation
Efficiency $=($ Final voltage/Initial voltage $) * 100$
Efficiency for 100 rotations $=(1.19 / 48) * 100=2.479 \%$

\section{Outline of the System}

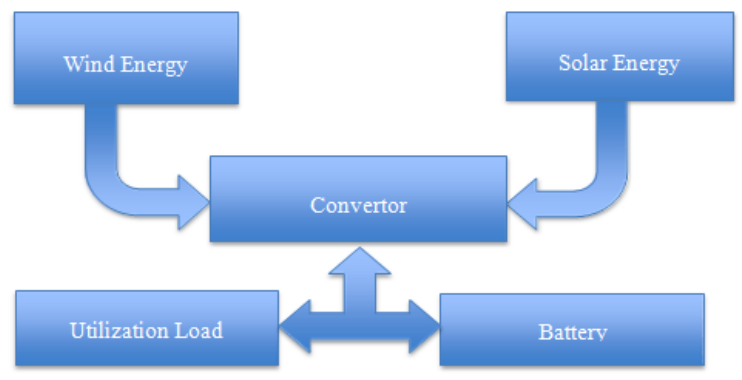

Figure 5. Outline Of The System

\subsection{Controller and Converter Stage}

Here in our project we are using DC-DC converter through buck boost converter. The buck-boost converter is a kind of DC-to-DC converter that earns voltage extent that is either more important than or not exactly the info voltage greatness. It is proportionate to a fly-back converter utilizing a solitary inductor rather than a transformer.

\subsection{Output Stage}

In day time the battery will be charged by solar panel. The circuit connected to the battery will convert the energy. Here we are using DC-DC buck boost converter to convert the energy. When the vehicle is in motion it will generates some wind and helps the turbine to rotate. The turbine will rotate the generator and produce some electricity. This electric power then converted by the converter and then goes to usage.

Then the energy generated by both solar and wind turbine hybrid together and now it is ready for usage. The new innovation on this project is we are going to utilize the $80 \%$ of the energy for direct usage and only $20 \%$ of the energy will give for the battery charging. By this way of using the energy we can reduce the conversion loss. 
Automatically when the loss is reduced the efficiency of the system will definitely increase.

\subsection{Conversion Of Wind Energy Into Electric Energy}

In this process wind turbine act as wind capturing device. Wind turbine is placed on the top of the vehicles. When the vehicle is in the motion it will provide some wind energy to rotate the wind turbine. Turbine was further connected to gear box to increase the speed of turbine. Then it rotates the $24 \mathrm{~V}$ generator and produce the electric energy. Then it converts using DC-DC converter and utilized for running the vehicles.

\subsection{Conversion Of Solar Power Into Electrical Energy}

At the day time solar energy can be used where, solar panel was placed on the top of the vehicle. When the sun light hits the solar panel, it is ready to produce the electric energy. It is worked on the following mechanism. When the light energy hit the anode part of the diode that is used in the solar panel tends to move the electrons towards the cathode so, in that way electric energy was produced in solar panels. Then this energy was converted using buck boost converter and is utilized.

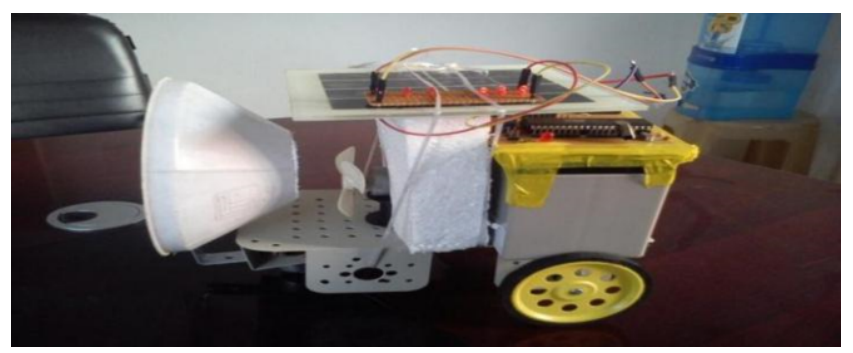

Figure 6. Electric Vehicle Using Hybrid Energy

\section{Conclusion}

After the energy was generated, we are going to utilize the $80 \%$ of the generated energy by using directly to running the vehicle by using the DC motor. The remaining $20 \%$ of the energy is stored in battery for backup usage. By this way of usage, we can improve the efficiency of the vehicle. The energy generated from wind turbine and solar panels are hybrid for usage. In day time solar energy is available, and wind energy is available when vehicle is in the motion. To increase the efficiency the $80 \%$ of the energy is given to direct utilization, rest $20 \%$ is given to battery for back up.

\section{Acknowledgement}

We might want thank Prof.S.M. Pimpalgaokar, Head of the Mechanical Building Department and Dr. N. K.Choudhari, Principalof our establishment. 


\section{References}

[1] "Design of a Wind Energy Capturing Device for a Vehicle. by Su-Huei Chang Department of industrialEducation National Taiwan Normal University Taipei, Taiwan-suggest the idea for the use of a portable wind turbine on a vehicle was obtained.

[2] hybrid solar and wind power: An Essential For Information Communication Technology Infrastructure And People in Rural Communities by I.A. Adejumobil, S.G.Oyagbinrin, F. G. Akinboro \& M.B. Olajide Electrical and Electronics Engineering Department, University of Agriculture,Abeokuta,NigeraVolumes/Vol9Issue1/(IJRRAS).

[3] Power estimation of hybrid model solar and wind Energy at Patiala.by Intermit Singh under the guidance of Mr.Souvik Gangly Assistant Professor (EIED)Thapar University, Patiala.

[4] Book -Renewable Energy Technologies a practical Guide for beginners by Chetan SinghSolanki.

[5] A Method for Generating Electricity by Fast Moving Vehicles. by S.Bharathi, G.Balaji, and M.Manoj KumarAngel College of Engineering \& Technology/ECE, Tirupur,India.

[6] G. Kudav, Y. Panta and M. Yatsco, Design and testing of wind deflectors for roof-mounted solar panels”, WIT Trans. on Egin. Sci., vol. 74, pp 15-27, July 2012.

[7] R Krishnan, Permanent Magnet Synchronus and brushless DC Motor drives, PHI,ch 9, pp 518-555

[8] Kavita Sharma, Prateek Haksar Designing of Hybrid Power Generation System using Wind EnergyPhotovoltaic Solar Energy- Solar Energywith Nanoantenna. InternationaJournal of Engineering Research And Applications (IJERA) Vol. 2, Issue 1,Jan-Feb 2012, pp.812-815

[9] Pallavi M. Mankar*, Atul A. Ghute *M.E.[EE] Student,Solar Powered Battery Operated Electric Vehicles an Option for Fuel Vehicle, International journal of engineering sciences and research technology (IJESRT) [Mankar, 4(4): April, 2015] ISSN: 2277-9655

[10] Study of Solar Energy Operated Hybrid Mild Cars:a Review. byRanjeet Singh, Manoj Kumar Gaur, Chandra Shekhar Malvi (International Journal of Scientific Engineering and Technology). Volume No.1, Issue No.4, pg.: 139- 148(ISSN: 2277-1581) 01 Oct. 2012.

[11]U.S. Department of Energy, $320 \%$ wind energy by 2030: increasingWindenergy's contributiontoU.S.HOHFWULFLW $\backslash 6$ XSSO $\backslash$ DOE/GO- 102008-2567, July2008.

[12] Solar Energy Perspectives: Executive Summary. (PDF). International Energy Agency. 2011. Archived from the original (PDF) on 13 January 2012.

[13] Energy. rsc.org. 2014-04-02.

[14]2014 Key World Energy Statistics. (PDF). iea.org. IEA. 2014. pp. 6, 24, 28. Archived (PDF) from the original on 5 April2015.

[15]"Energy and the challenge of sustainability" (PDF). United Nations DevelopmentProgramme and World Energy Council. September 2000. January2017.

[16] Use of Fossil energy. Smil (1991), p. 240

[17] Natural Forcing of the Climate System. Intergovernmental Panel on Climate Change. Archived from the original on 29 September 2007.Retrieved 